\title{
The nutritional state of children and adolescents with cerebral palsy is associated with oral motor dysfunction and social conditions: a cross sectional study
}

\author{
Vanessa Vieira Pinto, Levy Anderson César Alves, Fausto M. Mendes and Ana Lídia Ciamponi*
}

\begin{abstract}
Background: Cerebral palsy (CP) is the main cause of severe physical impairment during childhood and has commonly shown oral motor association. It has been considered as the main cause of the high prevalence of problems in children's nutrition. Respiration, chewing, swallowing, speaking and facial expressionare part of the orofacial motor functions and when affected they can interfere in children's well-being. The aim of this study was to correlate two methods of orofacial motor evaluation, analyze the influence of orofacial motor functional impairment on the nutritional status of children and adolescents with $\mathrm{CP}$, and the association between socioeconomic factors.
\end{abstract}

Methods: Seventy children and adolescents with CP were selected, age range 6-16 years and following the exclusion criteria previously determined; 129 normoreactive children (control group), sex and age-matched to patients with CP. For the orofacial motor analysis two evaluation instruments were applied, the "Oral Motor Assessment Scale" (OMAS) and "Nordic Orofacial Test-Screening" (NOT-S). The anthropometric evaluation was based on the World Health Organization (WHO) and followed the criteria recommended by the Brazilian Ministry of Health.

Results: There was statistically significant correlation between the oral motor methods of evaluation $(r=-0.439$, $p<0.0001)$. Concerning the nutritional status evaluation, being overweight was associated with dystonic and mixed CP forms variables $(p=0.034)$, mother with no partnership $(p=0.045)$ and mild oral motor impairment $(p=0.028)$.

Conclusion: It could be concluded that, the weight's gain by children and adolescents might be favored by a better functional oral motor performance and social factors.

Keywords: Children, Cerebral palsy, Nutrition, Oral motor function

\section{Background}

Cerebral palsy (CP) is a term used to describe a variety of non-progressive disorders of posture and movement associated to immature brain defect [1]. Motor, growth and nutritional disorders are very common in $\mathrm{CP}$ patients, and some factors such as malnutrition and endocrine disturbs have been reported in the literature as common conditions influencing patient's growth $[2,3]$.

\footnotetext{
* Correspondence: analidia@usp.br

Department of Orthodontics and Paediatric Dentistry, School of Dentistry,

University of São Paulo (USP), Avenida Professor Lineu Prestes 2227SP, São Paulo 05508-000, Brazil
}

(c) 2016 Pinto et al. Open Access This article is distributed under the terms of the Creative Commons Attribution 4.0 International License (http:/creativecommons.org/licenses/by/4.0/, which permits unrestricted use, distribution, and reproduction in any medium, provided you give appropriate credit to the original author(s) and the source, provide a link to the Creative Commons license, and indicate if changes were made. The Creative Commons Public Domain Dedication waiver (http://creativecommons.org/publicdomain/zero/1.0/) applies to the data made available in this article, unless otherwise stated.

Malnutrition has been considered a major worldwide problem and according to Dahlseng et al. [4] only $63 \%$ of children with $\mathrm{CP}$ have normal Body Mass Index (BMI), with $16 \%$ being overweight or obese and $20 \%$ with thinness or severe thinness. Children with $\mathrm{CP}$ used to be considered small for their age, however, recently such condition seems to be changed in many countries.

Rogozinski et al. [5] reported an increase of $8.8 \%$ in the prevalence of obesity among ambulatory children with CP from 1994-1997 to 2003-2004 in the US. Park et al. (2011) [6] also reported an increase in the prevalence of obesity among $\mathrm{CP}$ children in Korea, but lower 
than that observed from the US. Feeding problems are common associated with a poor linear growth. Few studies documented the association between chewing and swallowing problems and nutritional intake and growth [7]. Oral motor impairment may also potentially affect the functional capacity of children and their health quality of life [8]. Hence, studies relating the association between oral motor impairment and nutrition in children/ adolescents with $\mathrm{CP}$ must be reported, so as to support professionals when dealing with pathology.

It has been hypothised that there is a correlation between oral motor dysfunction and gross motor dysfunction and that it correlates with under nutrition, but to our knowledge there are no published studies assessing the association between oral motor dysfunction and nutritional status.

Therefore, the aim of this study was to evaluate the association of functional motor orofacial performance with the orofacial nutritional status of children/adolescents with $\mathrm{CP}$, evaluate the association between socioeconomic conditions, motor orofacial function and nutritional status, andthe correlation between two different motor assessment scales.

\section{Methods}

This is a cross-sectional study that was conducted at the University of São Paulo-Dental School, from January to December 2013. The study was conducted after obtaining ethical clearance from the Ethics in Research Committee of the Dental School - University of São Paulo/ BR (protocol n. 208/2010), according to the Helsinki Declaration.

A total of 110 children and adolescents, with age range 6-16 years with a clinical medical diagnosis of $\mathrm{CP}$ and attending the CAPE (Center of Attendance for Special Needs Patients) of the Dental School, University of São Paulo, Brazil, were potentially eligible to participate in the study. From that, those who were neurological immature and were not able to cooperate with the evaluation, with any chronic illness affecting growth other than $\mathrm{CP}$, those who went through surgical procedures such as selective dorsal ryzotomy, intratecal baclofen or botulin toxine treatment as well as those parents of children/adolescents who did not accept to participate in the study were excluded. Therefore, participants included 70 children/adolescents with CP (study group) age- and sex-matched to 129 clinically healthy children/ adolescents whose parents accepted to participate in the study (control group) and signed the written informed consent.

A questionnaire referring to demographic and socioeconomic data [9], as well as to general conditions of children/adolescents was administered to parents. Patients were clinically examined and their motor limitation was classified according to the Gross Motor Function Classification System (GMFCS) [10].

Some instruments of oral motor evaluation have been developed in search of knowledge of the oral motor function, to indicate affected area, evaluate intervention results, improve health attention and support the development of advanced treatment. Although the considerable effort aiming to establish ordinary criteria for this evaluation, the instruments available are still not used with frequency, for still being an area with very few studies.

In the present study, two instruments previously developed for the same aim were applied and correlated between themselves, as well as associated to the nutritional status of CP children and adolescents.

One of the instruments used was the NOT-S, though currently only a few studies have been available in the literature referring to the measurement of orofacial motor impairment [11-14] and none has been related to nutrition on $\mathrm{CP}$ individuals.

The OMAS was the other instrument used for this investigation, and was developed after the NOT-S, and maybe for that reason, there is still a little about this method. There is one study between young individuals with spastic cerebral palsy that investigated the influence of orofacial motor performance, given by the OMAS, nutritional status and salivary parameters. The complexity of those oral functional instruments is different and both have advantages and disadvantages.

With regards to the NOT-S instrument, it showed to be better than the OMAS as it does not involve meal costs, an advantage for population studies and/or for those studies which are developed in more distant areas and with little resources. In that case, people would need specific places to obtain food, and also adequate facilities to store them, for instance the yoghurt used for evaluation.

Though, the OMAS offered the advantage that it did not depend on the cooperation and direct interaction of the patient, once the examiner observes the individual during the repetition of daily actions when eating. The time spent during the evaluation process was not recorded, but it can be inferred that when using the OMAS the examiner spends less time and it occurs due to the smaller number of items evaluated and also because individuals do not have to understand how movements must be done.

Both instruments were chosen for the study due to their efficiency on identifying which areas of the oral motor function have been harmed. Besides, it is also possible to evaluate different levels of impairment comparing both groups (study and control), also, both of them meet high reliability standards and are translated and validated into Portuguese $[13,15]$. 
We evaluated whether there was any correlation between the instruments, since both aim to evaluate the same oral motor functions. This is the first study that correlates OMAS and NOT-S.

Patient oral motor performance was evaluated during the feeding process using the Brazilian validated version of NOT-S [16-18] and OMAS [15] (Kappa intraexamine $r=0.94$ and Kappa intraexamine $r=0.96$, respectively).

The NOT-S consists of a structured interview and a clinical examination, each comprising six domains: Interview - sensory function, breathing, habits, chewing and swallowing, drooling and the dryness of the mouth. Clinical examination - face at rest, nose breathing, facial expression, masticatory muscle and jaw function, oral motor function and speech [16].

For the OMAS, the following issues were evaluated: mouth closure, lip closure onto the utensils, lip closure during deglutition, control of food during swallowing (solid/semisolid), mastication, straw suction and control of liquids during deglutition. The final result was given by a score for each topic of the oral motor skill assessed [15].

The anthropometric evaluation was based on the WHO growth standards [16], following the criteria recommended by the Brazilian Ministry of Health, Feeding and Nutritional Surveillance System (SISVAN) [19] and recorded on the clinical form.

In order to evaluate the body weight of children/adolescents with $\mathrm{CP}$, the caregiver was weighed and the body mass was recorded in the evaluation form. Afterwards, the caregiver holding the child/adolescent was weighed and the total weight was recorded. The final weight was calculated by subtracting the total value and the caregiver weight. The height of $\mathrm{CP}$ patients was estimated, since they can present osteo-skeletal malformations, muscle spasms, cognitive impairment, disorder of equilibrium and seizures. Measurements of long bones were performed according to Stevenson's [20] methodology (Knee height $\times 2.69 / 24.2$ ). The knee height was measured using the Hardenden Antropometer with the knee and ankle being bent at a $90^{\circ}$ ). For typically developing children, the height was measured by means of a height rule (Welmy', W200A, Brazil).

The evaluation of the nutritional status was made by means of the Body Mass Index (BMI) Z-score and calculated by the AnthroPlus [21] software. The WHO and SISVAN standards propose the following cut-offs: overweight: > + 1SD, obesity: > + 2SD, severe obesity > +3 SD, thinness: <- 2SD, severe thinness: <-3SD.

\section{Statistical analysis}

In order to correlate the evaluation methods of oral motor function, the Spearman correlation coefficient was calculated. The association between the methods and some independent variables (group, types of $\mathrm{CP}$, and GMFCS) was evaluated by using the Poisson regression.

Concerning the outcomes of oral motor function and nutritional status, the findings were: overweight (eutrophy + thinness + severe thinness versus overweight + obesity + severe obesity) and underweight (eutrophy + overweight + obesity + severe obesity versus thinness + severe thinness). The independent variables (socioeconomic and clinical features of children/adolescents) tested were: OMAS, NOT-S, groups, form of CP (spastic versus dystonic + mixed), GMFCS, use of medication, mother's marital status (with or without partnership).

Concerning the association among the independent variables and both outcomes, oral motor functional performance and nutritional status, the Poisson regression analysis was performed. The significant variables $(<0.20)$ were included in a multivariate regression model.

The Poisson's regression analysis and Spearman's correlation were performed for data evaluation by using Stata 9.0 (Stata Corp LP, College Station, USA). The level of significance was set as $5 \%$ for all tests used.

\section{Results \\ Population characteristic}

Tables 1 and 2 show the mean values \pm standard deviation or $n$ (\%), respectively, for the socioeconomic and clinical variables, for both control and study groups.

\section{Oral motor evaluation}

The correlation values between oral motor evaluation indexes showed statistically significant $(P<0.0001)$ but inversely proportional $(r=-0.439 ; 95 \% \mathrm{CI}=-0.545$ to $-0.320)$ results.

Univariate Poisson's regression analysis demonstrated association between the oral motor evaluation methods (OMAS and NOT-S) for the groups, between the forms of CP and for the GMFCS $(\geq 4)$. There was association between dystonic and mixed types only for the NOT-S method.

With regards to the groups, $26 \%$ of the evaluated population of CP patients demonstrated worst scores for the OMAS, and 3 times greater for the NOT-S, compared to the healthy patients. Within the $\mathrm{CP}$ patients, the spastic group demonstrated the smallest scores for the OMAS and a greater level of impairment for the NOT-S, as well as for the dystonic and mixed forms (Table 3).

\section{Nutritional status evaluation}

In our study, Poisson Univariate regression analysis showed significant results for some of the independent variables, considering that children were above the weight (nutritional evaluation). A multivariate model 
Table 1 Clinical variables for the control and study group $(n=199)$

\begin{tabular}{|c|c|c|}
\hline & $\begin{array}{l}\text { Study group } \\
(N=70)\end{array}$ & $\begin{array}{l}\text { Control group } \\
(N=129)\end{array}$ \\
\hline Independent variables & $N(\%)$ or Mean \pm SD & $N(\%)$ or Mean \pm SD \\
\hline OMAS & $2.21 \pm 0.71$ & $3 \pm 0$ \\
\hline NOT-S & $6.5 \pm 0.71$ & $1.71 \pm 0.71$ \\
\hline \multicolumn{3}{|l|}{ Gender } \\
\hline male & $37(52.9)$ & $69(53.49)$ \\
\hline female & $33(47.1)$ & $60(46.51)$ \\
\hline Age & $11.81 \pm 3.09$ & $11.5 \pm 3$ \\
\hline \multicolumn{3}{|l|}{ Birth $^{a, b}$} \\
\hline Fullterm & $34(49.28)$ & $112(86.82)$ \\
\hline preterm & 35 (50.72) & 17 (13.18) \\
\hline \multicolumn{3}{|l|}{ Birthweight ${ }^{a, c}$} \\
\hline normal & $32(46.38)$ & $114(88.37)$ \\
\hline low & $16(23.19)$ & $12(9.3)$ \\
\hline very low weight & $21(30.43)$ & $3(2.33)$ \\
\hline \multicolumn{3}{|l|}{ Type of CP } \\
\hline spastic & $51(72.86)$ & 0 \\
\hline dystonic and mixed & $19(27.14)$ & 0 \\
\hline \multicolumn{3}{|l|}{ GMFCS } \\
\hline I & $1(1.43)$ & $129(100)$ \\
\hline$\|$ & $26(37.14)$ & 0 \\
\hline III & $1(1.43)$ & 0 \\
\hline IV & $3(4.29)$ & 0 \\
\hline V & $39(55.71)$ & 0 \\
\hline
\end{tabular}

Nutritional status

$\begin{array}{lll}\text { eutrophy } & 35(50) & 91(70.54) \\ \text { thinness } & 4(5.71) & 4(3.1) \\ \text { severe thinness } & 4(5.71) & 0 \\ \text { overweight } & 15(21.43) & 21(16.28) \\ \text { obesity } & 5(7.15) & 11(8.53) \\ \text { severe obesity } & 7(10) & 2(1.55) \\ \text { Use of medication (yes) } & 51(72.86) & 5(3.88) \\ \text { Medication } & & 0 \\ \text { anticonvulsant } & 31(44.29) & 1(0.78) \\ \text { tranquilizer } & 20(28.57) & 4(3.1) \\ \text { others } & 22(31.43) & 129(100) \\ \text { Feeding } & & 0 \\ \text { alone } & 35(50) & 0 \\ \text { needs help } & 27(38.57) & \\ \text { gastric probe } & 8(11.43) & 24(18.6) \\ \text { Impaired health (yes) } & & 2(1.55) \\ \text { sight } & 36(51.43) & 38(29.46) \\ \text { listening } & 8(11.43) & 21(30)\end{array}$

Table 1 Clinical variables for the control and study group $(n=199)$ (Continued)

\begin{tabular}{lll}
\hline cardiovascular system & 0 & $1(0.78)$ \\
others & $1(1.43)$ & $2(1.55)$ \\
$\begin{array}{l}\text { Cognitive } \\
\text { normal }\end{array}$ & \\
mild-moderate disorder & $37(52.86)$ & $129(100)$ \\
severe disorder & $33(47.14)$ & 0
\end{tabular}

$S D$ : mean standard deviation

${ }^{a} 1$ responsible for the study group did not inform about birth weight

bFullterm: between 37 and 41 weeks pregnant, preterm: $<37$ weeks

'Normal: $2.5 \mathrm{Kg}$ to $4 \mathrm{Kg}$, low: $<2.5 \mathrm{Kg}$ to $1.5 \mathrm{Kg}$, very low weight: $<1.5 \mathrm{Kg}$

Table 2 Socioeconomic variables for the control and study group

\begin{tabular}{|c|c|c|}
\hline & $\begin{array}{l}\text { Study group } \\
(N=70)\end{array}$ & $\begin{array}{l}\text { Control group } \\
(N=129)\end{array}$ \\
\hline Independent variables & $n(\%)$ or Mean \pm SD & $n(\%)$ or Mean \pm SD \\
\hline $\begin{array}{l}\text { Caretaker with health } \\
\text { impairment }^{a}\end{array}$ & $20(28.57)$ & $26(20.15)$ \\
\hline Caregiver - mother & $58(82.86)$ & $122(94.57)$ \\
\hline Caregiver's age & $38.05 \pm 6.36$ & $38.78 \pm 10.6$ \\
\hline Father's age & $42.88 \pm 6.36$ & $41.2 \pm 8.48$ \\
\hline Aglomeration & $1.08 \pm 0.06$ & $1.01 \pm 0$ \\
\hline \multicolumn{3}{|l|}{ Home } \\
\hline ownership & $53(75.71)$ & $102(79.07)$ \\
\hline rented and donated & $17(24.29)$ & $27(20.93)$ \\
\hline \multicolumn{3}{|l|}{ Mother's marital status } \\
\hline partnership & $40(57.14)$ & $102(79.07)$ \\
\hline no partnership & $30(42.86)$ & $27(20.93)$ \\
\hline Number of children & $2.18 \pm 1.41$ & $2.58 \pm 2.83$ \\
\hline \multicolumn{3}{|c|}{ Parents school degree ${ }^{\mathrm{b}}$ (mother/father) } \\
\hline$\leq 8$ years & $45(64.3) / 45(67.16)$ & $75(60) / 65(56.03)$ \\
\hline$>8$ years & $25(35.71) / 22(32.83)$ & $50(40) / 51(43.97)$ \\
\hline \multicolumn{3}{|l|}{ Employed $^{c}$} \\
\hline mother & $23(33.33)$ & $66(52.8)$ \\
\hline father & $55(87.3)$ & $100(87.72)$ \\
\hline \multicolumn{3}{|l|}{ Full time occupation } \\
\hline mother & $15(21.43)$ & $48(37.2)$ \\
\hline father & $45(71.43)$ & $96(74.42)$ \\
\hline $\begin{array}{l}\text { Earned income } \\
\text { (brazilian minimum wages) }\end{array}$ & $2.7 \pm 1.25$ & $2.9 \pm 0.57$ \\
\hline \multicolumn{3}{|c|}{$\begin{array}{l}\text { SD: mean standard deviation } \\
\text { aCaregiver mentioned having health problem } \\
\text { bIn the study group, } 3 \text { guardians did not know father's school degree, in the } \\
\text { control group } 4 \text { guardians did not know mother's school degree and } 13 \\
\text { father's school degree } \\
\text { 'In the study group, } 5 \text { could not inform mother's occupation and } 7 \text { father's } \\
\text { occupation. In the control group } 4 \text { could not inform mother's occupation and } \\
15 \text { father's occupation }\end{array}$} \\
\hline
\end{tabular}


Table 3 Univariate Regression Analysis for the association between the independent variables and the oral motor evaluation methods

\begin{tabular}{|c|c|c|c|c|}
\hline \multirow[b]{2}{*}{ Variables } & \multicolumn{2}{|l|}{ OMAS } & \multicolumn{2}{|l|}{ NOT-S } \\
\hline & RR $(95 \% \mathrm{Cl})$ & $P^{*}$ & $\mathrm{RR}(95 \% \mathrm{Cl})$ & $P^{*}$ \\
\hline $\begin{array}{l}\text { Group } \\
\text { Control group }\end{array}$ & $0.74(0.65-0.84)$ & $<0.001$ & $3.79(3.33-4.31)$ & $<0.001$ \\
\hline CP form & & & & \\
\hline spastic & $0.67(0.56-0.79)$ & $<0.001$ & $3.90(3.40-4.47)$ & $<0.001$ \\
\hline $\begin{array}{l}\text { Dystonic and } \\
\text { mixed }\end{array}$ & $0.93(0.83-1.04)$ & 0.261 & $3.50(2.89-4.23)$ & $<0.001$ \\
\hline GMFCS & $0.87(0.82-0.91)$ & $<0.001$ & $1.34(1.29-1.39)$ & $<0.001$ \\
\hline
\end{tabular}

$\mathrm{RR}=$ rate ratio; $95 \% \mathrm{Cl}=95 \%$ confidence interval

*Calculated by the Wald's test

was designed considering the significant variables previously observed (Table 4).

Table 4 shows the association for overweight variables and demonstrates that patients with $\mathrm{CP}$, whose mother reported having no partnership, showed a greater prevalence of being overweight, as well as the ones who presented mild oral motor impairment, given by the evaluation scores (OMAS). Regarding the $\mathrm{CP}$ forms, dystonic and mixed were statistically significant, pointing that there is a greater prevalence for those who are overweight.

In the Poisson's Univariate regression analysis of the nutritional status evaluation for underweight children/ adolescents, the variables which demonstrated significance were those related with oral motor dysfunction (OMAS and NOT-S), birth weight, use of medication (anticonvulsant, tranquilizer), feeding, cognitive impairment, GMFCS and father's occupation (Table 5). Though, when designing the multivariate model, the variables lose significance.

Table 4 Possion's Final Regression Model used to evaluate the associations between the independent variables for the overweight outcome

\begin{tabular}{lll}
\hline Variables & PR ajusted $(95 \% \mathrm{Cl})$ & $P^{*}$ \\
\hline Mother's marital status (with partnership) & & \\
Without partnership & $0.57(0.33-0.98)$ & 0.045 \\
Respiratory system (Normal) & $1.63(0.97-2.74)$ & 0.062 \\
Impaired & & \\
Cardiovascular system (Normal) & $5.36(0.71-40.03)$ & 0.101 \\
Impaired & $2.46(1.10-5.53)$ & 0.028 \\
OMAS (Continuous Variable) & & \\
CP form (control group) & $1.72(0.90-3.29)$ & 0.100 \\
$\quad$ spastic & $2.12(1.05-4.26)$ & 0.034 \\
$\quad$ Dystonic and mixed & & \\
\hline
\end{tabular}

*Calculated by the Wald's test

$\mathrm{PR}=$ prevalence ratio; $95 \% \mathrm{Cl}=95 \%$ Confidencelnterval

Variables in parenthesis refers to the reference group
Table 5 Poisson's Univariate Regression Analysis for the association between the independent variables and the underweight condition

\begin{tabular}{|c|c|c|}
\hline Variables & Crude PR (95 \% Cl) & $p^{*}$ \\
\hline OMAS (continuous variable) & $0.44(0.31-0.62)$ & $<0.001$ \\
\hline NOT-S (continuous variable) & $1.19(1.03-1.36)$ & 0.014 \\
\hline \multicolumn{3}{|l|}{ Birth (term) } \\
\hline preterm & $2.80(0.94-8.34)$ & 0.063 \\
\hline \multicolumn{3}{|l|}{ Birth weight (normal) } \\
\hline Low weight + very low weight & $3.93(1.30-11.87)$ & 0.015 \\
\hline Very low weight (low weight) & $1.79(1.05-3.05)$ & 0.031 \\
\hline Anticonvulsant & $3.87(1.30-11.45)$ & 0.014 \\
\hline Tranquilizer & $4.23(1.39-12.91)$ & 0.011 \\
\hline $\begin{array}{l}\text { Feeding (eating by him/herself) with } \\
\text { help + sonda }\end{array}$ & $4.03(2.27-7.17)$ & $<0.001$ \\
\hline Feeding help (normal) & $3.64(0.87-15.24)$ & 0.077 \\
\hline Probe (normal) & $16.4(4.40-61.07)$ & $<0.001$ \\
\hline Cognitive impairment (moderate) Severe & $2.81(1.47-5.38)$ & 0.002 \\
\hline GMFCS (continuous variable) & $1.68(1.22-2.31)$ & 0.001 \\
\hline \multicolumn{3}{|l|}{ Mother's School degree ( $\leq 8$ years) } \\
\hline$>8$ years & $0.14(0.01-1.10)$ & 0.063 \\
\hline \multicolumn{3}{|l|}{ Father's occupation (no) } \\
\hline yes & $14.15(8.64-23.17)$ & $<0.001$ \\
\hline
\end{tabular}

*Calculated by the Wald's test

$\mathrm{PR}=$ prevalence ratio; $95 \% \mathrm{Cl}=95 \%$ Confidencelnterval

\section{Discussion}

The oral motor evaluation was performed by means of the OMAS instrument and demonstrated that patients with $\mathrm{CP}$ have a greater prevalence of lower scores (less ability) when compared tohealthy patients. Meanwhile, the NOT-S instrument, showed higher scores, which reveals greater impairment.

Among the type of $\mathrm{CP}$ patients, the spastic ones were the group presenting greater oral motor impairment. This might have occurred because spastic CP children/ adolescents were the ones with a greater level of impairment and demonstrated difficulties to cooperate or did not understand the reproducibility of the movements, which reinforces the advantage of using the OMAS instrument in these conditions. An analysis of both scales, based on our clinical experience, showed that the OMAS can be more recommended as it does not depend upon patient's cooperation, understanding of required movements and direct interaction between patient-examiner throughout the evaluation. Additionally, the mean time spent to complete the OMAS analysis was smaller compared to the other scale.

For the gross motor function the greater the score on the scale $(\geq 4)$, the greater the orofacial motor impairment, demonstrating that $\mathrm{CP}$ may lead to a greater impairment of oral motor facial function. 
Beyond the correlation between the methodologies, we tried to associate orofacial motor function with the nutritional status of children/adolescents with CP.

Studies in nutritional area evaluating problems related to nutrition in people with neuromotor disability have been mainly performed in developed countries [22-24], and have been scarce in developing countries.

Among the literature findings, there are also some studies reporting the results of underweight children [14]. Though, Rogozinski et al. [5] reported that the obesity prevalence within ambulatory $\mathrm{CP}$ children increased in the USA, from $7.7 \%$ during the period of 1994-1997 to $16.5 \%$ in between 2003 and 2004. Know et al. [25] also reported the prevalence of obesity and being overweight to be $14.6 \%$ for the ambulatory patients with CP in Korea, but they did not show an increase along the recent years. Moreover, it has been reported in the literature that weight excess and the risk of weight excess between CP patients are greater than in general population [26].

Therefore, our results are in agreement with those findings, unraveling that out of the eutrophic condition, the majority of the $\mathrm{CP}$ population was overweight. The possible causes could be little or non-existent physical activity between $\mathrm{CP}$ children/adolescents, due to physical limitations, lack of accessibility at school playground and/or in the gym, cognitive difficulties which can also affect the interaction within those activities, or even tiring and muscle pain, leading to sedentary lifestyle [22]. Among those patients, dystonic and mixed forms demonstrated a greater prevalence to be overweight, probably due to the mild orofacial motor impairment feature and also because they can feed themselves with less trouble.

Family structure, or parental union status, is an important aspect of family context which has been associated to the development of many children. However, very little is known about how the family structure can affect nutritional health of children [27, 28]. It seems that children with stable single mothers have larger gains in BMI and higher risk of becoming overweight or obese [28]. According to Schmeer [28], the study models for BMI show that economic resource changes due to family dissolution, less social or emotional support and a smaller participation of parents can lead to an increase in child's stress during this transition period, thus, resulting in an increase in BMI, and consequently a greater risk of becoming overweight/obese.

With regards to thinness or severe thinness, having better oral motor ability (greater scores for OMAS and smaller scores for NOT-S) and better gross function were identified as a protective factor, as the feeding improves, and less problems caused by poor nutrients intake occur. The association with severe impaired cognition may occur because of the difficulties faced by caregivers in knowing the right demand of food, time between meals and the amount required. Despite the small number of children fed by means of a probe, there was a strong association between the fact of being underweight and this way of nutrition. Calis et al. [29] also observed an association of tube feeding and lower anthropometric Z-scores.

Although the research has reached its aims, there were some limitations that occurred due to individual's intellectual impairment to cooperate during evaluation. Besides, this is an observational study with a convenience sample, which may have influenced the results. More studies should be done with higher number of underweight patients.

\section{Conclusions}

From the data collected, we could conclude that:

- There is significant correlation between oral motor evaluation instruments OMAS and NOT-S;

- A better oral facial functional performance favors the gain of weight in CP children and adolescents, independent on the gross motor function. Dystonic $\mathrm{CP}$ children/adolescents presented mild impairment of the oral motor function, compared to the spastic ones.

- There is a significant association between nutritional status and mother's marital status, which suggest that social factors may interfere with the assessed outcome.

Competing interests

The authors declare that they have no competing interests. This study was supported by CAPES/Br and FAPESP.

Authors' contributions

WP and ALC were responsible for the study design, WP and LACA were involved in data collection. FMM was responsible for the statistical analysis. All authors were involved in the writing of the manuscript. All authors read and approved the final manuscript.

\section{Acknowledgments}

The authors wish to thank all of the volunteers for their participation in this study.

Received: 18 June 2015 Accepted: 14 April 2016

Published online: 26 April 2016

\section{References}

1. Fung EB, Samson-Fang $L$, Stallings VA, et al. Feeding dysfunction is associated with poor growth and health status in children with cerebral palsy. J Am Diet Assoc. 2002;102:361-73.

2. Tomoum HY, Badawy NB, Hassan NE, Alian KM. Anthropometry and body composition analysis in children with cerebral palsy. Clin Nutr. 2010;29:477-81.

3. Kuperminc MN, Stevenson RD. Growth and nutrition disorders in children with cerebral palsy. Dev Disabil Res Rev. 2008;14:137-46.

4. Dahlseng MO, Finbraten AK, Juliusson PB, Skranes J, Andersen G, Vik T. Feedingproblems, growth and nutritional status in children with cerebral palsy. Acta Pediatr. 2012;101:92-8. 
5. Rogozinski BM, Davids JR, Davis RB, et al. Prevalence of obesity in ambulatory children with cerebral palsy. J Bone Joint Surg Am. 2007;89:2421-6.

6. Park ES, Chang WH, Park JH, Yoo JK, Kim SM, Rha DW. Childhood obesity in ambulatory children and adolescents with spastic cerebral palsy in Korea. Neuropediatrics. 2011;42:60-6.

7. Sullivan PB, Juszczak E, Lambert BR, et al. Impact of feeding problems on nutritional intake and growth: Oxford Feeding Study II. Dev Med Child Neurol. 2002;44:461-7.

8. Liu WY, Hou YJ, Wong AM, et al. Relationships between gross motor functions and health- related quality of life of Taiwanese children with cerebral palsy. Am J Phys Med Rehabil. 2009:88:473-83.

9. Jarman B. Identification of underprivileged areas. BMJ. 1983;286:1705-9.

10. Palisano RJ, Rosenbaum P, Walter $\mathrm{S}$, et al. Development and reliability of a system to classify gross motor function in children with cerebral palsy. Dev Med Child Neurol. 1997:39:214-23.

11. Strini PJSA, Strini PJSA, Barbosa TD, et al. Assessment of orofacial dysfunctions, salivary cortisol levels and oral health related quality of life (ORHQoL) in young adults. Arch of Oral Biol. 2010;56:1521-7.

12. Marquezin MC, Kobayashi FY, Montes $A B$, et al. Assessment of masticatory performance, bite force, orthodontic treatment need and orofacial dysfunction in children and adolescents. Arch OralBiol. 2013;58:286-92.

13. Bergendal B, McAllister A, Stecksen-Blicks C. Orofacial dysfunction in ectodermal dysplasias measured using the Nordic Orofacial Test-Screening protocol. Acta Odontol Scand. 2009;67:377-81.

14. Cunningham K, Gibney MJ, Kelly A, et al. Nutrient intakes in long-stay mentally handicapped persons. Br J Nutr. 1990;64:3-11.

15. Ortega Ade O, Ciamponi AL, Mendes FM, et al. Assessment scale of the oral motor performance of children and adolescents with neurological damages. J Oral Rehabil. 2009;36:653-9.

16. WHO Growth reference data for 5-19 years: WHO reference 2007; 2007. Available from: http://www.who.int/growthref/en/. (accessedJun 23, 2011).

17. Bakke M, Bergendal B, McAllister A, et al. Development and evaluation of a comprehensive screening for orofacial dysfunction. Swed Dent J. 2007;31:75-84.

18. Leme MS Tradução e validação do instrumento Nordic Orofacial TestScreening (NOT-S) e avaliação da associação entre disfunção orofacial e qualidade de vida relacionada à saúde bucal em crianças e adolescentes entre 8 e 14 anos. Dissertação, 2010. Universidade Estadual de Campinas.

19. SISVAN Ministério da Saúde do Brasil. Sistema de Vigilância Alimentar e Nutricional- SISVAN; 1996. Available from: http://nutricao.saude.gov.br/ sisvan.php?conteudo=curvas_cresc_oms (accessed June 23, 2011).

20. Stevenson RD. Use of segmental measures to estimate stature in children with cerebral palsy. Arch Pediatr Adolesc Med. 1995;149:658-62.

21. WHO AnthroPlus WHO AnthroPlus for personal computers Manual: Software for assessing growth of the world's children and adolescents; 2009.Available from: http://www.who.int/growthref/tools/en/. (accessedJune 23, 2011).

22. Rimmer $J H$, Rowland JL, Yamaki K. Obesity and secondary conditions in adolescents with disabilities: addressing the needs of an underserved population. J Adolesc Health. 2007:41:224-9.

23. Troughton KEV, Hill AE. Relation between objectively measured feeding competence and nutrition in children with cerebral palsy. Dev Med Child Neurol. 2001;43:187-90.

24. Motion S, Northstone K, Emond A, et al. Early feeding problems in children with cerebral palsy: weight and neurodevelopmental outcomes. Dev Med Child Neurol. 2002;44:40-3.

25. Kwon DG, Kang SC, Chung CY, Lee SH, Lee KM, Choi IH, Cho TJ, Yoo WJ, Park YJ, Park MS. Prevalence of obesity in ambulatory patients with cerebral palsy in the Korean population a single institution's experience. Clin Orthop Surg. 2011;3:211-6.

26. Hurvitz EA, Green LB, Hornyak JE, et al. Body mass index measures in children with cerebral palsy related to gross motor function classification: a clinic-based study. Am J Phys Med Rehabil. 2008:87:395-403.

27. Carr D, Springer KW. Advances in Families and Health Research in the 21st Century. J MarFam. 2010;72:743-61.

28. Schmeer KK. Family structure and obesity in early childhood. Soc Sci Res. 2012;41:820-32.

29. Calis EA, Veugelers R, Rieken R, Tibboel D, Evenhuis HM, Penning C. Energy intake does not correlate with nutritional state in children with severe generalized cerebral palsy and intellectual disabilitity. Clin Nutr. 2010;29:617-21.

\section{Submit your next manuscript to BioMed Central and we will help you at every step:}

- We accept pre-submission inquiries

- Our selector tool helps you to find the most relevant journal

- We provide round the clock customer support

- Convenient online submission

- Thorough peer review

- Inclusion in PubMed and all major indexing services

- Maximum visibility for your research

Submit your manuscript at www.biomedcentral.com/submit
() BioMed Central 